\title{
New physiological activities of myosuppressin, sulfakinin and NVP-like peptide in Zophobas atratus beetle
}

\author{
Pawel Marciniak • Mariola Kuczer • \\ Grzegorz Rosinski
}

Received: 5 October 2010/Revised: 17 February 2011/Accepted: 23 February 2011/Published online: 16 March 2011

(C) The Author(s) 2011. This article is published with open access at Springerlink.com

\begin{abstract}
Three neuropeptides Zopat-MS-2 (pEDVDHVFLRFa), Zopat-SK-1 (pETSDDYGHLRFa) and ZopatNVPL-4trunc. (GRWGGFA), recently isolated from the neuroendocrine system of the Zophobas atratus beetle, were tested for their myotropic and hyperglycaemic activities in this species. These peptides exerted differentiated dose-dependent and tissue specific physiological effects. Zopat-MS-2 inhibited contractions of the isolated heart, ejaculatory duct, oviduct and hindgut of adult beetles and induced bimodal effects in the heart contractile activity of pupae in vivo. It also increased the haemolymph free sugar level in larvae of this species, apart from myotropic activity. Zopat-SK-1 showed myostimulatory action on the isolated hindgut of the adult beetles, but it decreased contractions of the heart, ejaculatory duct and oviduct. Injections of this peptide at a dose of $2 \mu \mathrm{g}$ also caused delayed cardioinhibitory effects on the heartbeat of the pupae. Together with the ability to increase free sugar level in the haemolymph of larvae these were new physiological activities of sulfakinins in insects. Zopat-NVPL-4trunc. inhibited the muscle contractions of the two organs: hindgut and ejaculatory duct but it was inactive on the oviduct and the heart of the adult beetles. This peptide also increased free sugar level concentration in the haemolymph of $Z$. atratus larvae. These physiological actions are the first biological activities discovered for this group of the
\end{abstract}

Communicated by G. Heldmaier.

P. Marciniak $(\bowtie) \cdot$ G. Rosinski

Department of Animal Physiology and Development,

Adam Mickiewicz University, Poznan, Poland

e-mail: pmarcin@amu.edu.pl

M. Kuczer

Faculty of Chemistry, Wroclaw University, Wrocław, Poland insect peptides. The present work showed pleiotropic activity of three neuropeptides and indicates that the visceral muscle contractions and the haemolymph sugar homeostasis in Z. atratus are regulated by complex mechanisms.

Keywords Insect neuropeptides - Zophobas atratus beetle $\cdot$ Myotropic activity

\section{Introduction}

In insects, neuropeptides are important messenger molecules that can act as neurotransmitters, neuromodulators or classical hormones (Nässel 2002). Recently, neuropeptidomes of several species have been explored and a huge number of peptide hormones have been isolated (Audsley and Weaver 2006; Clynen and Schoofs 2009; Hummon et al. 2006; Li et al. 2008; Predel et al. 2008, 2010; Verleyen et al. 2004). However, physiological actions of most of the identified peptides remain undiscovered (De Loof 2008) or have mainly been studied by usage of heterologous bioassays (Nässel 2002).

In Coleopterans, the largest insect order, only several neuropeptides have been identified (Weaver and Audsley 2008) and neuropeptidome of only one species Tribolium castaneum was studied ( $\mathrm{Li}$ et al. 2008). Information on physiological actions of majority of the neuropepties in this insect order is unknown. Recently, we identified several neuropeptides from the Zophobas atratus adult beetle (Marciniak et al. 2010b). Here, we report new physiological activities of three peptides myosuppressin Zopat-MS-2, sulfakinin Trica-SK-1, and NVP-like peptide Trica-NVPL4trunc. in this beetle species. To better clarify these as $Z$. atratus endogenous peptides, we rename previously 
identified peptides Trica-SK-1 and Trica-NVPL-4trunc. as Zopat-SK-1 and Zopat-NVPL-4trunc., respectively, according to recently published paper on insect neuropeptide nomenclature by Coast and Schooley (2010).

Myosuppressins are a group of FMRFamide related peptides characterized by C-terminal sequence X1DVX2HX3FLRFa (where $\mathrm{X} 1=\mathrm{pE}, \mathrm{P}, \mathrm{T}$ or $\mathrm{A}, \mathrm{X} 2=\mathrm{D}, \mathrm{G}, \mathrm{V}$ and $\mathrm{X} 3=\mathrm{V}$ or $\mathrm{S}$ ). First neuropeptide from this family, leucomyosuppressin (pEDVDHVFLRFa, LMS) was isolated in 1986 from the cockroach Leucophaea maderae (Holman et al. 1986). Myosuppressins are widely known as inhibitors of visceral muscles, such as the foregut, hindgut, oviduct, heart and Malpighian tubules (Lange et al. 1991; Orchard et al. 2001; Skonieczna and Rosinski 2004). Few bioanalogs, such as SchistoFLRFa enhance the force of neurally evoked contractions of the skeletal muscles (Elia and Orchard 1995). Moreover, it was showed that myosuppressins inhibit the release of the adipokinetic hormones from corpora cardiaca (Vullings et al. 1998) and are involved in feeding regulations in insects (Audsley and Weaver 2009).

Insect sulfakinins are neuropeptides characterized by sulfated tyrosine residues, C-terminal sequence $\mathrm{Y}\left(\mathrm{SO}_{3} \mathrm{H}\right)$ GHMRFa and structural and functional similarities to vertebrate gastrin and cholecystokinin (Schoofs and Nachman 2006). The first peptide hormone of this family was isolated from L. maderae by its ability to stimulate the hindgut contractions (Nachman et al. 1986). Currently, sulfakinins are known mainly as the gut and heart contraction modulators in several insect species (Schoofs and Nachman 2006). They also inhibit the food uptake in locusts and cockroaches and stimulate the release of the digestive enzymes in the scallop Pecten maximus and insect Rhynchophorus ferrugineus (Nachman et al. 1997). Recent studies suggest that non-sulfated peptides can also fulfill their biological functions (Nichols et al. 2009). Nonsulfated form of sulfakinin was detected in Z. atratus brain (Marciniak et al. 2010b), so in this studies we report its physiological properties in the beetle.

Several insect peptides, such as NVP-like peptides (NVPL) have been named after their partial N-terminal sequence. The first hormones from NVPL family were found in a peptidomic study of the honey bee brain (Hummon et al. 2006). MS analysis yielded seven peptides from the NVPL peptide family in T. castaneum ( $\mathrm{Li}$ et al. 2008). Recently, we found Zopat-NVPL-4trunc. in the brain, CC/CA neurosecretory complex and ventral nerve cord of Z. atratus (Marciniak et al. 2010b). Thus far their function and status as neuropeptides remain unclear.

In this paper, we report the first myotropic and hyperglycaemic actions of NVPL peptide in insects. Furthermore, we confirm myostimulatory activity of sulfakinins and discover its myoinhibitory and hyperglycaemic activities. Myosuppressin are proved to be myoinhibitory peptides in beetles. In addition, the organ specific myoregulatory activity of all three hormones are compared.

\section{Materials and methods}

Insects

Zophobas atratus Fab. adults (2- to 4-week old), pupae (1day old) and last instar larvae (just after moult, body weight $600-800 \mathrm{mg}$ ) were obtained from a colony maintained at the Department of Animal Physiology and Development, Adam Mickiewicz University according to the Quennedy procedure (Quennedey et al. 1995).

Peptides

Peptides were synthesized by the classical solid phase method according to the Fmoc-procedure (Fields and Noble 1990). Amino acids were assembled either on a Wang (peptide acids) or Rink amide MBHA resin (peptide amides). As a coupling reagent HBTU in the presence of HOBt was used. The N-Fmoc group was removed with $20 \%$ piperidine in $N, N$-dimethylformamide (DMF). The peptideresin was cleaved with trifluoroacetic acid (TFA) in the presence of ethanedithiol (EDT). All peptides were purified by preparative HPLC on a Varian ProStar column-Tosoh Biosciences ODS-120T C18 (ODS $300 \times 21.5 \mathrm{~mm}$ ). Analytical HPLC was performed with a Thermo Separation Products with a VYDAC $\mathrm{C}_{18}$ column (ODS $250 \times$ $4.6 \mathrm{~mm}$ ). The molecular weights of the peptides were determined with a Bruker Daltonics microTOF-Q mass spectrometer (USA). Synthetic peptides were dissolved in saline A $\left(274 \mathrm{mM} \mathrm{NaCl}, 19 \mathrm{mM} \mathrm{KCl}, 9 \mathrm{mM} \mathrm{CaCl}_{2}, 5 \mathrm{mM}\right.$ glucose, and $5 \mathrm{mM}$ HEPES, $\mathrm{pH}$ 7.0) for in vitro bioassays or saline $\mathrm{B}\left(274 \mathrm{mM} \mathrm{NaCl}, 19 \mathrm{mM} \mathrm{KCl}, 9 \mathrm{mM} \mathrm{CaCl}_{2}\right)$ for in vivo bioassays to yield a stock solution of $1 \mathrm{mM}$ and they were stored at $-30^{\circ} \mathrm{C}$. Working dilutions were made from the stock solution in appropriate saline.

In vitro heart bioassay

In the bioassay, the microdensitometric method was used to measure peptide effects on the semi isolated heartbeat frequency of the adult beetle (Rosinski and Gäde 1988). In this method many pulse applications $(10 \mu \mathrm{l})$ of samples could be sequentially assayed in a single preparation. After the initial $15 \mathrm{~min}$ stabilization, the control activity of the isolated heart was recorded for $0.5 \mathrm{~min}$. Next, the sample was applied and the heart activity was recorded for further $1.5 \mathrm{~min}$. The activities of the tested peptides were presented as percentage changes in the control frequency of the heart contractions. 
In vivo heart bioassay

The in vivo heart bioassay was conducted on 1 day old $Z$. atratus pupae by means of noninvasive optocardiographic technique of Slama and Rosinski (Slama and Rosinski 2005) as described previously (Marciniak et al. 2010a). The heart rhythm was recorded for $24 \mathrm{~h}$. Sample injections were performed after $2 \mathrm{~h}$ of initial stabilization of pupae heartbeat rhythm. Changes in the heartbeat frequency after injection were recorded and compared to the control rhythm (physiological saline injection). To each pupae the recording started always at the same time of the day.

Ejaculatory duct, oviduct and hindgut in vitro videomicroscopy bioassays

In the bioassays, a video microscopy technique and the computer-based method of data acquisition and analysis were used to study the action of the peptides on the frequency contractions of the continuously perfused preparations of ejaculatory duct, oviduct or hindgut as described previously (Marciniak and Rosinski 2010). The superfusion system and incubation chamber were similar to those used in the heart bioassay. The activities of tested peptides were presented as percentage changes in the control frequency of the ejaculatory duct or oviduct contractions. The hindgut bioassay was performed exactly the same way as the reproductive tract bioassays.

\section{Haemolymph sugar bioassay}

Hyperglycaemic activity of the peptides was tested in the $Z$. atratus larvae according to the previously described bioassay (Rosinski and Gäde 1988). Peptides were injected in an adequate concentration range through the ventral membrane between the second and the third abdominal segments toward the head, into the larvae just after ecdysis. Control insects were injected by saline B. Haemolymph samples $(2 \mu \mathrm{l})$ were collected just before and two hours after injections. The samples were mixed with $500 \mu \mathrm{l}$ of $70 \%$ ethanol and shaken several minutes to obtain full extraction of free sugar. The extracts were centrifuged at $10,000 \times g$ for $4 \mathrm{~min}$ and the supernatants were used for free sugar concentration analysis (Dubois et al. 1956) using trehalose as a standard.

\section{Results}

Effect of peptides on the adult and pupa heartbeat

The Z. atratus adult heart rhythm in vitro remained regular during superfusion with saline $\mathrm{A}$ and showed on average
$34 \pm 6$ beats/min. Application of two of the tested peptides Zopat-SK-1 and Zopat-MS-2 caused fast, dosedependent and reversible decrease of the heart contractile activity (not shown). Zopat-NVPL-4trunc. showed no significant effects on the myocardium frequency contractions in the whole concentration range of the peptide tested (Fig. 1c). A comparison of the dose-response curves indicated that Zopat-SK-1 was more potent cardioinhibitory peptide than Zopat-MS-2 (Fig. 1). EC 50 value determined for this peptide $\left(1.1 \times 10^{-11} \mathrm{M}\right)$ was much lower than for myosuppressin $\left(5.6 \times 10^{-7} \mathrm{M}\right)$. However, the maximal cardioinhibitory effect induced by Zopat-SK-1 (25\% inhibition in comparison to saline A injection) was twofold smaller in comparison to the action of Zopat-MS-2 (55\% inhibition).

Both cardioinhibitory peptides were also tested for their activity in vivo on the 1-day-old $Z$. atratus pupae. Heart rhythm of pupae was manifested by the regular alternations of the forward orientated (anterograde), the backward orientated (retrograde) cardiac pulsations together with diastasis as described previously (Marciniak et al. 2010a). The heartbeat frequency in control insects showed on average 30 beats/min in anterograde phase and 12 beats/min in retrograde phase. Zopat-SK-1 retained cardioinhibitory properties in vivo (Fig. 2b). Injection $2 \mu \mathrm{g}$ of the peptide induced a delayed negative chronotropic effect in the both phases of the heart contractile activity in comparison to injection of saline B, which caused no effect (Fig. 2a). The cardioinhibitory effect started $8 \mathrm{~h}$ after the peptide injection and it intensified to $18 \mathrm{~h}$ after injection. Cardioinhibitory in vitro peptide Zopat-MS-2 in vivo showed bimodal actions on the heart contractile activity of pupae (Fig. 2c). Injection of $2 \mu \mathrm{g}$ of this peptide caused the positive chronotropic effect in the anterograde phase of the heart contractions. Maximal cardiostimulatory effect of the peptide was observed $10 \mathrm{~h}$ after injection. The heartbeat contraction rhythm in this phase remained higher even $20 \mathrm{~h}$ after peptide injection. An opposite cardioinhibitory effect Zopat-MS-2 showed in the retrograde phase. It gradually decreased the myocardium contractions from $6 \mathrm{~h}$ after injection and after $20 \mathrm{~h}$ the contraction frequency was still lower than the control frequency. Lack of a clear statistically significant differences in comparison to saline injections were indicated due to large fluctuations of the pupal heartbeat rate.

Myoregulatory activity of peptides

on the reproductive organs

The ejaculatory duct of the $Z$. atratus adult male during perfusion with saline A showed irregular contractions with the frequency on average $4 \pm 2$ contractions/min. All three peptides tested caused mainly myoinhibitory reversible effects on the ejaculatory duct contractions (Fig. 3a-c). 

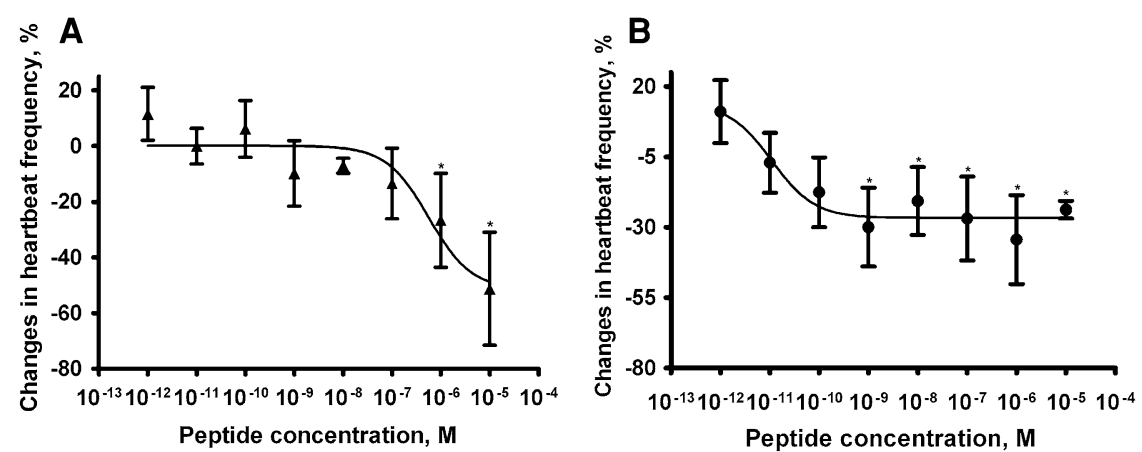

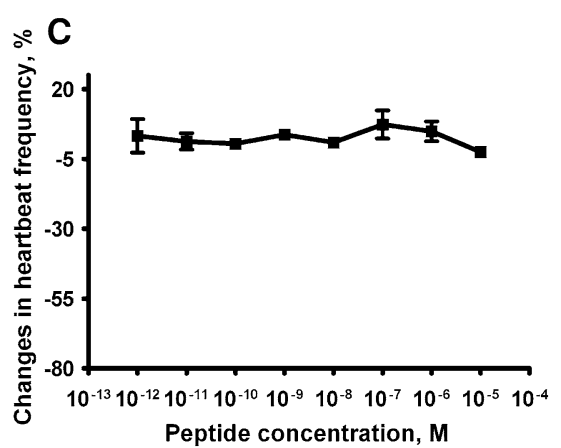

Fig. 1 Changes compared to control in the heartbeat frequency of adult beetles after application of Zopat-MS-2 (a), Zopat-SK-1 (b) and Zopat-NVPL-4trunc. (c). Mean \pm SEM are given from at least eight determinations. Statistically significant differences $(P \leq 0.05)$ in heartbeat frequency from control (saline A application) are indicated by asterisks ( $t$ student test)
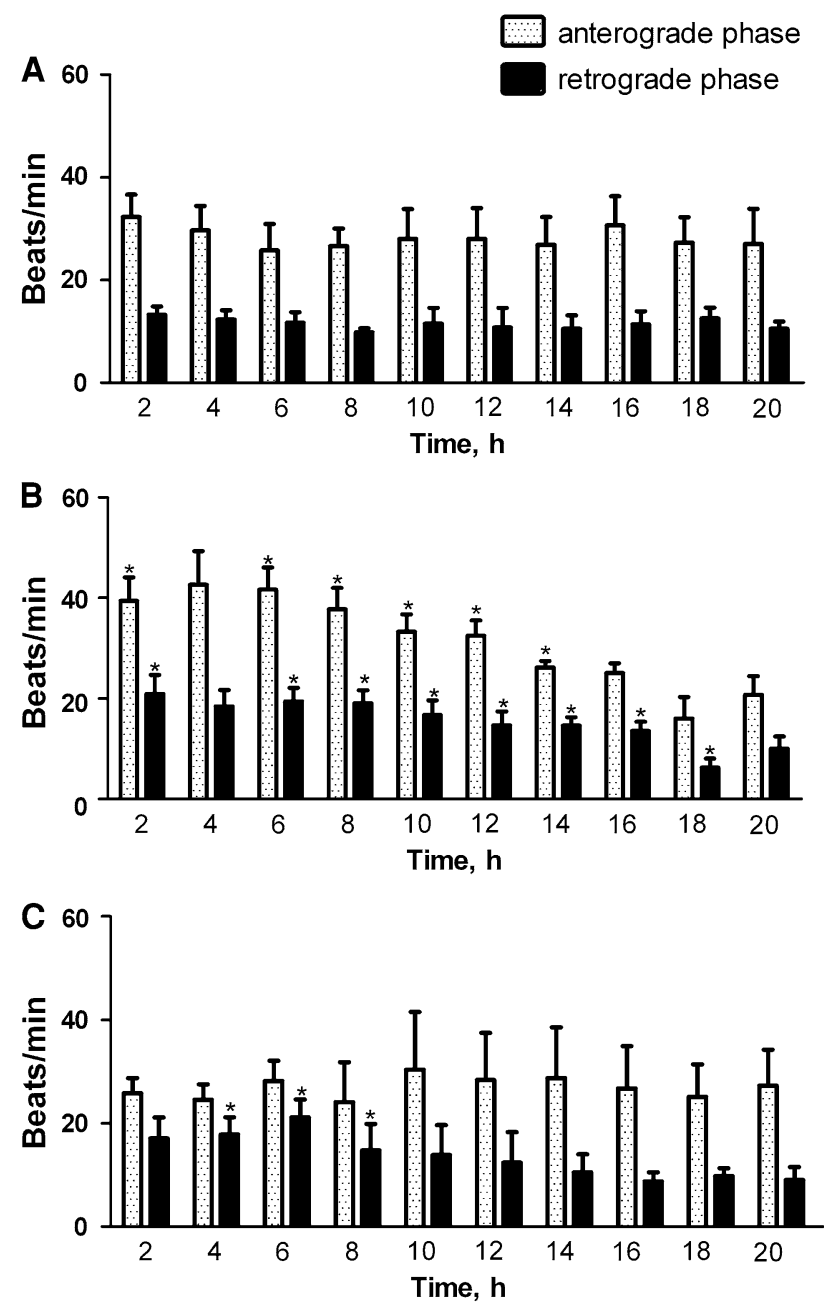

Fig. 2 The heartbeat contraction rhythm in anterograde and retrograde phases of 1-day old pupae of $Z$. atratus up to $20 \mathrm{~h}$ after injection of saline B (a), Zopat-SK-1 (b) and Zopat-MS-2 (c). Mean \pm SEM are given from at least eight determinations. Statistically significant differences $(P \leq 0.05)$ from control (saline B injection) are indicated by asterisks ( $t$ student test)
As on the heart, application of Zopat-MS-2 caused inhibition of the ejaculatory duct contractions in majority of the tested concentration range (Fig. 3a). Maximal myoinhibitory effect of peptide (85-90\% inhibition) was observed in concentration $10^{-5} \mathrm{M}$ where it caused short arrests in contraction activity of this organ. More potent in inhibition of the ejaculatory duct contractions was ZopatSK-1 (Fig. 3b). Sulfakinin caused inhibition in almost whole tested concentration range $\left(10^{-12}-10^{-5} \mathrm{M}\right)$, however, it induced the strongest effect ( $80 \%$ of inhibition) in $10^{-10} \mathrm{M}$ whereas the weakest effect in $10^{-5} \mathrm{M}$. Calculated $\mathrm{EC}_{50}$ values for all three peptides tested (Table 1) indicated that the most potent inhibitory peptide on the ejaculatory duct of Z. atratus was Zopat-NVPL-4trunc. In low concentration range $\left(10^{-12}-10^{-10} \mathrm{M}\right)$ it caused no significant effects. In higher concentrations $\left(10^{-7}-10^{-5}\right)$ it inhibited contractions of the ejaculatory duct by $50-60 \%$ (Fig. 3c). The $\mathrm{EC}_{50}$ value for this peptide $\left(7.6 \times 10^{-10} \mathrm{M}\right)$ was only a slightly lower than for Zopat-SK-1 $\left(8.4 \times 10^{-9} \mathrm{M}\right)$.

The oviduct of $Z$. atratus adult female showed irregular contraction frequency with a level $14 \pm 7$ contractions/ min during superfusion with saline A. Application of the tested peptides caused fast, dose-dependent and reversible effects on the oviduct contraction frequency.

Zopat-MS-2 was a weak inhibitor of the oviduct contractions. The peptide caused the strongest effect (inhibition by 20\%) when it was applied in pharmacological concentration $10^{-5} \mathrm{M}$ (Fig. 4a). The most potent myoinhibitory peptide which was tested on the oviduct was SK-1. It caused inhibition in almost all concentration range $\left(10^{-12}-10^{-7} \mathrm{M}\right)$. The strongest myoinhibitory effect was observed in concentration $10^{-10} \mathrm{M}$, and the weakest in $10^{-5} \mathrm{M}$ (Fig. 4b). Similar to Zopat-MS-2 Zopat-NVPL4trunc. was also weak inhibitor of the oviduct contractions (Fig. 4c). No significant changes in contractions frequency were observed in the tested concentration except $10^{-5} \mathrm{M}$, however, the effect was very weak (10\% inhibition). 

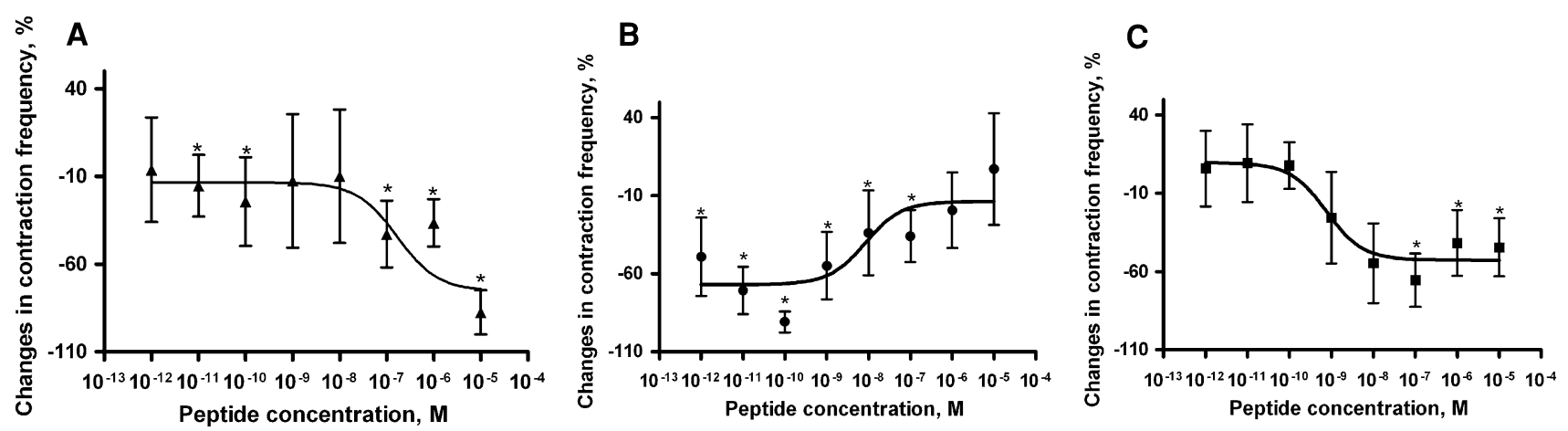

Fig. 3 Changes compared to control in the ejaculatory duct contractions frequency of $Z$. atratus adult males after application of ZopatMS-2 (a), Zopat-SK-1 (b) and Zopat-NVPL-4trunc. (c). Mean \pm SEM are given from at least eight determinations. Statistically significant differences $(P \leq 0.05)$ from control (saline A) are indicated by asterisks ( $t$ student test)

Table $1 \mathrm{EC}_{50}$ values calculated for the effects of peptides on the contraction frequency of $Z$. atratus visceral muscles

\begin{tabular}{llll}
\hline Tested organ & Peptide & & \\
\cline { 2 - 4 } & Zopat-MS-2 & Zopat-SK-1 & Zopat-NVPL-4trunc. \\
\hline Heart & $\downarrow 5.6 \times 10^{-7} \mathrm{M}$ & $\downarrow 1.1 \times 10^{-11} \mathrm{M}$ & - \\
Ejaculatory duct & $\downarrow 1.7 \times 10^{-7} \mathrm{M}$ & $\downarrow 8.4 \times 10^{-9} \mathrm{M}$ & $\downarrow 7.6 \times 10^{-10} \mathrm{M}$ \\
Oviduct & $\downarrow 0.6 \mathrm{M}$ & $\downarrow 2.5 \times 10^{-7} \mathrm{M}$ & $\downarrow 0.2 \mathrm{M}$ \\
Hindgut & $\downarrow 9.4 \times 10^{-8} \mathrm{M}$ & $\uparrow 2.7 \times 10^{-9} \mathrm{M}$ & $\downarrow 8.3 \times 10^{-8} \mathrm{M}$ \\
\hline
\end{tabular}

$\uparrow$ stimulation

$\downarrow$ inhibition

Effects of peptides on the hindgut contractions

The hindgut of the $Z$. atratus adult, superfused with physiological saline A showed irregular contractions activity with a level $5 \pm 4$ contractions per minute. The tested peptides caused differentiated myotropic effects on the hindgut.

Zopat-MS-2 induced myoinhibitory effect in concentration range of $10^{-6}-10^{-5} \mathrm{M}$. Its application decreased the hindgut contractions by $50 \%$. In low concentrations
$10^{-12}-10^{-8} \mathrm{M}$ the hindgut contractions rhythm remained unchanged (Fig. 5a). Only one tested peptide Zopat-SK-1 increased the hindgut contractions frequency (Fig. 5b). This peptide stimulated contractions in almost whole tested concentration range $\left(10^{-12}-10^{-5} \mathrm{M}\right)$. The strongest effect (almost $100 \%$ stimulation) caused application of low physiological concentrations of Zopat-SK-1 $\left(10^{-12}\right.$ $10^{-9} \mathrm{M}$ ), whereas, its concentrations from $10^{-8}$ to $10^{-5} \mathrm{M}$ stimulated hindgut by $20 \%$ when compared to control application of saline B. However, these results were not

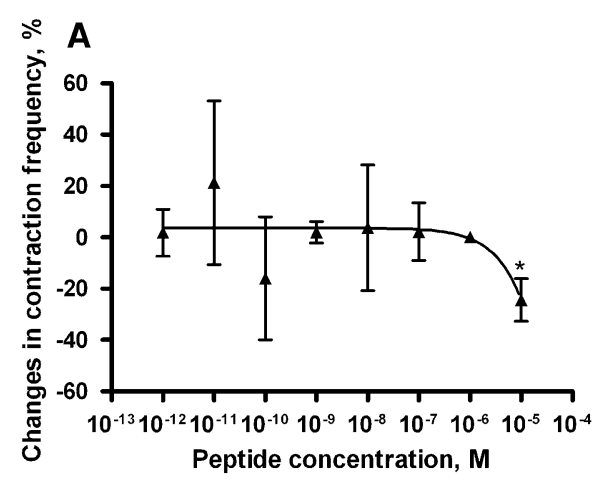

Fig. 4 Changes compared to control in the oviduct contractions frequency of $Z$. atratus adult females after application of Zopat-MS-2 (a), Zopat-SK-1 (b) and Zopat-NVPL-4trunc. (c). Mean \pm SEM are
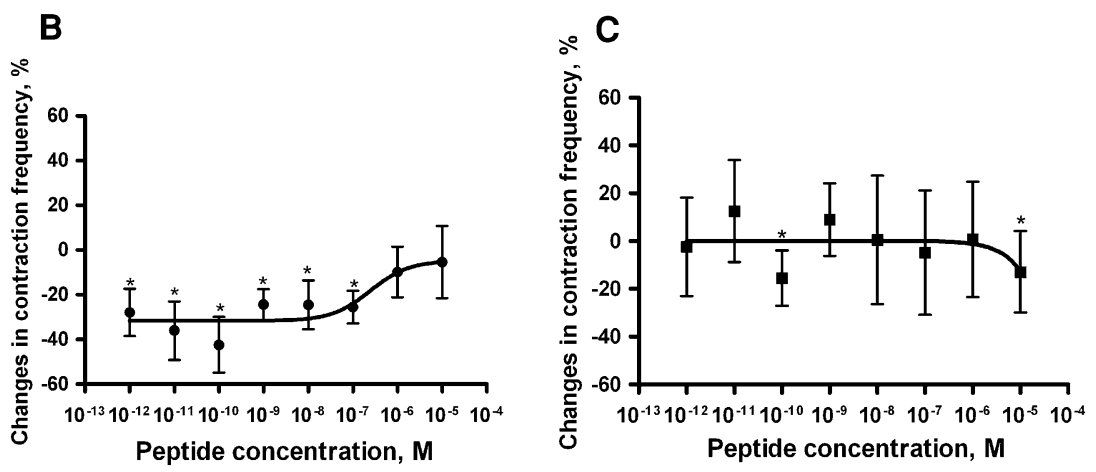

given from at least eight determinations. Statistically significant differences $(P \leq 0.05)$ from control (saline A) are indicated by asterisks ( $t$ student test) 

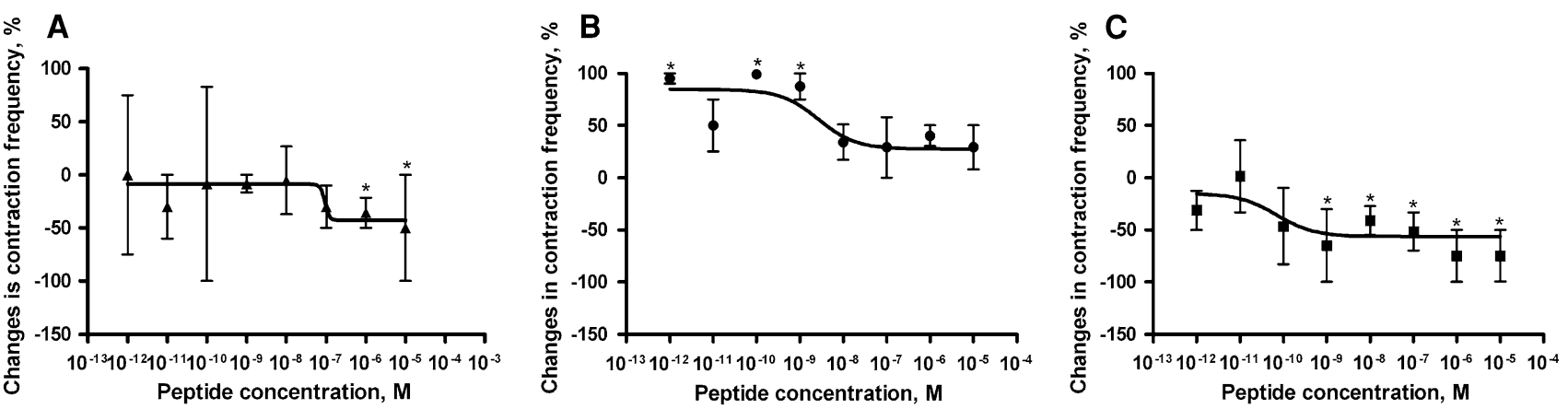

Fig. 5 Changes compared to control in the hindgut contraction frequency of Z. atratus adults after application of Zopat-MS-2 (a), Zopat-SK-1 (b) and Zopat-NVPL-4trunc. (c). Mean \pm SEM are given

statistically significant. Similar effect to myosuppressin was produced by Zopat-NVPL-4trunc. This peptide also inhibited the gut contractions with a level 50\% (Fig. 5c). However, threshold concentration for observable effects was lower $\left(10^{-8} \mathrm{M}\right)$ than in Zopat-MS-2 $\left(10^{-7} \mathrm{M}\right)$. In concentration range of $10^{-8}-10^{-5} \mathrm{M}$ the inhibitory effects remained on the same level (50\% inhibition).

\section{Hyperglycaemic activity of peptides}

The experiments demonstrated hyperglycaemic activity of peptides. Injections of 1,2 and $4 \mu \mathrm{g}$ of all three peptides tested increased the haemolymph sugar level in freshly moulted $Z$. atratus larvae. As the phenol-sulphuric acid method for carbohydrates determinations does not give any information on the nature of the free sugars in the haemolymph, we identified sugars qualitatively by thin-layer chromatography. The predominant haemolymph sugar in $Z$. atratus larvae was the disaccharide trehalose ( $>90 \%$ of total sugars) accompanied by very small amounts of glucose, fructose and maltose (data not shown). Therefore, we use the more general therm "hyperglycaemia" instead of "hypertrehalosaemia" in this context, since only total haemolymph free sugars were determined.

The strongest hyperglycaemic effects were caused by Zopat-SK-1. Injection of $4 \mu \mathrm{g}$ of this peptide increased haemolymph sugar level by $150 \%$ (Fig. 6). A similar effect occurred after injection of $2 \mu \mathrm{g}$, however, it was much weaker (increased by 50-60\%). Two other tested peptides Zopat-NVPL-4trunc. and Zopat-MS-2 increased the sugar level by $100 \%$. Hyperglycaemic effect of ZopatMS-2 remained still after injection of $2 \mu \mathrm{g}$ with a level of $75 \%$, whereas injections of 1 and $2 \mu \mathrm{g}$ of Zopat-NVPL4trunc. caused no effects. A similarly $1 \mu \mathrm{g}$ of Zopat-MS-2 caused no effect in the haemolymph sugar concentrations (Fig. 6). However, these effects were not statistically significant. from at least eight determinations. Statistically significant differences $(P \leq 0.05)$ from control (saline A) are indicated by asterisks ( $t$ student test)

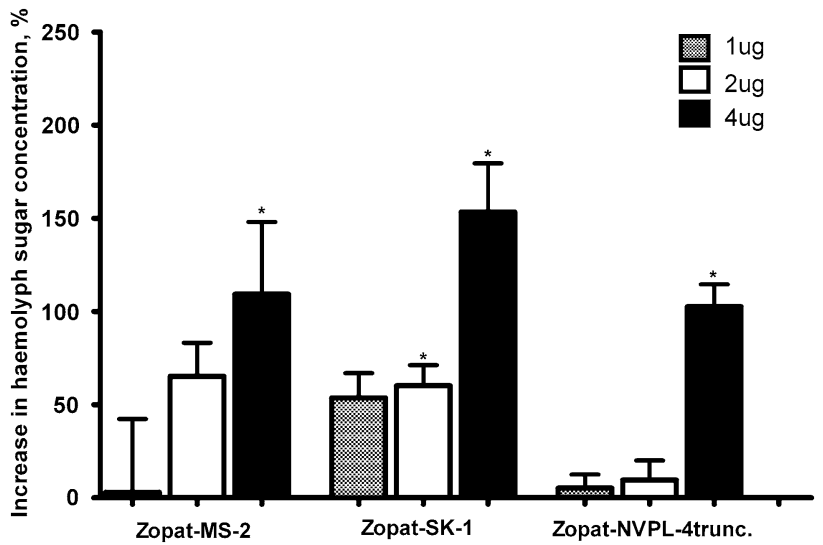

Fig. 6 Changes in haemolymph free sugar concentration in the larvae injected with the different doses of Zopat-MS-2, Zopat-SK-1, ZopatNVPL-4trunc. Columns represent mean \pm SEM from at least five determinations. Statistically significant differences $(P \leq 0.05)$ from control (saline B injection) are indicated by asterisks ( $t$ student test)

\section{Discussion}

In this study we examined myotropic and hyperglycaemic activities of three peptides Zopat-MS-2, Zopat-SK-1 and Zopat-NVPL-4trunc. isolated recently from neuroendocrine system of the Z. atratus beetle. Previous studies on the different physiological effects caused by hormones in this beetle were performed only in heterologous bioassays by usage of peptides from other insect species (Marciniak and Rosinski 2010; Skonieczna and Rosinski 2004; Sliwowska et al. 2001). Three tested neuropeptides caused differentiated, dose-dependent and organ specific physiological activity. A few newly discovered myotropic and glycaemic activities were new physiological properties of myosuppressins, sulfakinins and NVPL peptides in insects.

\section{Effects of Zopat-MS-2}

The decapeptide Zopat-MS-2 is a member of myosuppressin family, which belongs to a large, structurally 
diverse group of peptides related to FMRFamide (FaRPs) with pleiotropic activity (Nässel 2002). The beetle Z. atratus is a second insect, after L. migratoria, with two identified myosuppressins LMS (pEDVDHVFLRFa) and Zopat-MS-2 (pEDVEHVFLRFa) (Marciniak et al. 2010b). Thus far, the most ubiquitous peptide from this group was leucomyosuppressin (LMS) (Orchard and Lange 2006). The physiological activity of LMS and other FaRPs was studied in several insects, including beetles, with different myotropic and metabotropic bioassays (Orchard et al. 2001; Wasielewski and Skonieczna 2008).

In all myotropic bioassays, myosuppressin 2 showed inhibition of the frequency contraction of visceral muscles. It was the most effective on the hindgut $\left(\mathrm{ED}_{50}=9.4 \times\right.$ $\left.10^{-8} \mathrm{M}\right)$. MS-2 was less effective on the ejaculatory duct $\left(\mathrm{ED}_{50}=1.7 \times 10^{-7} \mathrm{M}\right)$, heart $\left(\mathrm{ED}_{50}=5.6 \times 10^{-7} \mathrm{M}\right)$ and oviduct $\left(\mathrm{ED}_{50}=0.6 \mathrm{M}\right)$. In comparison to LMS, which caused inhibition of cockroach L. maderae oviduct contractions in concentrations $10^{-10}-10^{-7} \mathrm{M}$ (Cook and Wagner 1991) and locust $L$. migratoria oviduct contractions with a threshold $10^{-7} \mathrm{M}$ (Peeff et al. 1993), Zopat-MS-2 is a weaker inhibitor of the oviduct contractions. Interestingly, FMRFa prompted contrary myotropic effect on the Z. atratus beetle oviduct. It stimulated the contraction frequency of the isolated oviduct and ejaculatory duct of adult beetles (Marciniak and Rosinski 2010). In comparison to FMRFa this difference is probably caused by the replacement $\mathrm{M} / \mathrm{L}$ in C-terminal sequence of myosuppressin (-FLRFa). The C-terminal fragment -FLRFa is a core sequence essential for myosuppressin activity (Orchard et al. 2001).

Zopat-MS-2 only partially retained its cardioinhibitory activity in in vivo studies. It inhibited the frequency of contractions in the retrograde phase and stimulated in the anterograde phase of the heart activity. This effect was different from the one produced by LMS. Injection of LMS into pupae of $Z$. atratus caused no changes in the frequency contractions but significantly reduced duration of both the anterograde and retrograde phases (Skonieczna 2006). This shows that both peptides LMS and Zopat-MS-2, despite the fact that they belong to the same neuropeptide family, act with different manner in the regulation of the heart activity. The possible reason for this is minor structural difference in amino acid composition of peptides. Zopat-MS-2 differs from leucomyosuppressin only by a conservative substitution of glutamic acid (E) for aspartic acid (D) at position 4 (Marciniak et al. 2010b). Interestingly in in vivo studies on the heart of $Z$. atratus both peptides were cardioinhibitory, however, LMS was a stronger inhibitor than ZopatMS-2. The threshold concentration for cardioinhibitory effect of LMS was at $10^{-9} \mathrm{M}$ (Skonieczna and Rosinski 2004) whereas for Zopat-MS-2 at $10^{-7} \mathrm{M}$. The maximal effect for LMS was also stronger than for Zopat-MS-2 (Skonieczna and Rosinski 2004).
Myosuppressin peptides inhibited contractions of different parts of alimentary tract in insects (Fuse and Orchard 1998). Previous studies showed that myosuppressin isolated from $S$. gregaria Scg-MS (PDVDHFLRFa) prompted bimodal effects in the contraction frequency of the $Z$. atratus larvae hindgut. It stimulated contractions at $10^{-7} \mathrm{M}$ and inhibited the contraction frequency in pharmacological concentrations range of $10^{-5}-10^{-3} \mathrm{M}$ (Skonieczna 2006). Myosuppressin 2 tested in our studies also decreased the contraction frequency. The inhibitory activity on the alimentary tract movement of $Z$. atratus and other insects demonstrates that peptides from this family are food uptake regulators (Audsley and Weaver 2009). Together with myoinhibitory action on the gut Zopat-MS-2 caused also hyperglycaemic activity. Similar effects showed LMS in $T$. molitor and Z. atratus larvae (Skonieczna 2006; Wasielewski and Skonieczna 2008). Possible mechanism of hyperglycaemic activity is stimulation of trehalose synthesis in fat body and/or an increase release of it into the haemolymph. This also suggests glycogenolitic activity of LMS in the fat body tissue of Z. atratus (Skonieczna 2006).

Myoregulatory and hyperglycaemic activities of sulfakinin

Thus far, sulfakinins were showed as peptides with pleiotropic activity in hemi- and holometabolic insects (Schoofs and Nachman 2006). The main physiological functions of these peptides were connected with the feeding regulation (Audsley and Weaver 2009) and modulation of the cardiac pulsation in cockroaches and flies (Nichols et al. 2002). Myotropic properties of sulfakinins were studied mainly by the usage of the gut and heart bioassays (Schoofs and Nachman 2006). They were shown to stimulate gut contractions of cockroach L. maderae (Nachman et al. 1986) and D. melanogaster (Nichols 2007), however, in some flies C. vomitoria and Phormia regina they caused no effects (Duve et al. 1994; Haselton et al. 2006). Sulfakinin found in Z. atratus showed the pleiotropic activity-myotropic and glycaemic. In the myotropic actions we showed tissue specific effect of the peptide. In Z. atratus, SK-1 was a strong stimulator of the hindgut muscle contractions, but it inhibits also the frequency of contractions of the oviduct, ejaculatory duct and heart. These are the new myotropic activities of sulfakinins in insects. In Z. atratus, similarly to D. melanogaster (Nichols 2007), the active form was nonsulfated peptide found in the neuroendocrine system of this beetle. The bioassays performed in this study showed that sulfakinins are not only involved in feeding regulation but also in the reproduction and haemolymph circulation.

Cardioinhibitory effect caused by Zopat-SK-1 on the $Z$. atratus heart was observed in the threshold concentration of $10^{-11} \mathrm{M}$ and was different from actions on the heart of 
other insect species. For example, sulfakinins in $P$. americana showed cardiostimulation in the threshold concentration of $10^{-11} \mathrm{M}$ (Predel et al. 1999). In D. melanogaster, drosulfakinins were cardiostimulatory in all tested developmental stages (larva, pupa, adult) (Nichols et al. 2009). In this studies Nichols et al. proved, that nonsulfated peptides nsDSKI (FDDYGHMRFa) and nsDSKII (GGDDQFDDYGHMRFa) also maintain cardioactivity and tyrosine sulfation is not crucial for binding of the peptides with receptor in myocardium. nsDSKI increased the heart contractions rate by $25 \%$ in larvae whereas nsDSKII increased the contractions rhythm by $38 \%$ in larvae and by $65 \%$ in adults (Nichols et al. 2009). All nonsulfated peptides were less cardiostimulatory than their sulfated forms. Our results obtained in this study are similar. Nonsulfated Zopat-SK-1 also maintains its physiological activity, however, we observed cardioinhibitory rather than cardiostimulatory effect. No data are avalible on activity of sulfated peptides in Z. atratus. Cardioinhibitory activity of SK-1 was also observed in pupae in in vivo bioassay. Inhibition was observed up to $18 \mathrm{~h}$ after peptide injection. It proves that sulfakinin are involved in regulation of haemolymph circulation in Z. atratus. In contrast to D. melanogaster non sulfated peptides affect also the pupal heart.

No data are available on involvement of sulfakinins in the reproductive organ motility. In this work we showed for the first time myoinhibitory properties of sulfakinins on the female (oviduct) and male (ejaculatory duct) muscles of the reproductive organs in insects. It is surprising that for the oviduct the strongest inhibitory effect of Zopat-SK-1 was observed in the lowest concentration of the peptide. Similar effect was observed on the heart and hindgut. The reason for this is unclear. Maybe higher concentrations of sulfakinins caused the receptor desensitization. Thus far, no information are accessible for the biology of sulfakinin receptor in Z. atratus. Further, detailed studies are needed to explain this effects. Inhibition of the oviduct muscle contractions may block oocyte movement through this organ and affect reproduction. Similarly a decrease of the ejaculatory duct contractions may arrest sperm transfer to the female and result also in reproduction disorders.

The another new physiological activity showed in this work was hyperglycaemic action of Zopat-SK-1 in larvae of $Z$. atratus. This effect was lower than caused by endogenic adipokinetic/hipertrehalosaemic peptide TenmoAKH (pELNFSPNWa) in adults of Zophobas atratus (Gäde and Rosinski 1990). However, previous studies showed that hyperglycaemic response in beetles was stage dependent. In Tenebrio molitor, the effects were more potent in larvae when compared to adults after the same peptide dose injections (Gäde and Rosinski 1990). Clearly, further studies are needed to unravel the hyperglycaemic mechanism of action for sulfakinins in beetles.
New physiological activities of Zopat-NVPL-4trunc.

We showed first physiological activities of NVPL peptide in insects. Thus far role of this peptide group as neurotransmitters, neuromodulators or classical hormones remain unknown. To date, bioanalogs of NVPL peptides have been found only in A. mellifera (Hummon et al. 2006), T. castaneum ( $\mathrm{Li}$ et al. 2008) and recently in Z. atratus (Marciniak et al. 2010b).

Identified in $Z$. atratus heptapeptide Zopat-NVPL4trunc. inhibited significantly muscle contractions of two visceral organs, the ejaculatory duct and hindgut of Z. atratus adults. Effects of neuropeptides on the insects ejaculatory duct were studied to a limited extent. Rankin et al. (2009) showed that proctolin stimulated ejaculatory duct contractions of $E$. annulipes at low concentrations range $\left(10^{-9}-10^{-7} \mathrm{M}\right)$ whereas at high concentrations $\left(10^{-5} \mathrm{M}\right)$ caused no significant effect. Proctolin stimulated also the ejaculatory duct muscle contractions of Z. atratus and T. molitor beetles (Marciniak and Rosinski 2010) and induced contractions of the male accessory gland of G. bimaculatus (Kimura et al. 1989). Peptides with myoinhibitory activity on the ejaculatory duct, but only at a higher concentration range, were allatostatin AST A in E. annulipes (Rankin et al. 2009) and FMRFamide in beetles T. molitor and Z. atratus (Marciniak and Rosinski 2010). In the Z. atratus males, peptide NVPL-4trunc. inhibited the ejaculatory duct contractions by $50 \%$ in concentration range $10^{-9}-10^{-5} \mathrm{M}$. It is the most active from thus far tested on the ejaculatory duct insects neuropeptides. Zopat-NVPL-4trunc. also decreased the contraction frequency of $Z$. atratus adults hindgut. This peptide caused the biggest inhibition of the gut contractions (50\%) from all of three tested peptides. Apart from myotropic activities it also induced hyperglycaemic effects after injection into larvae of $Z$. atratus. However, the hyperglycaemic response caused by Zopat-NVPL4trunc. was weaker in comparison to the effect produced by Zopat-MS-2 and Zopat-SK-1. In order to elucidate the mechanism of action of Zopat-NVPL-4trunc. further experiments are required.

In conclusion, we tested three peptides isolated from $Z$. atratus in myotropic and glycaemic bioassays. We confirm that myosuppressins have not only myoinhibitory properties on the visceral muscle contractions but also possess the hyperglycaemic activity. Zopat-SK-1 was a stimulator of the hindgut contractions and also inhibited the heart, ejaculatory duct and oviduct contractions. These are new physiological activities of sulfakinins in insects together with ability to the increase of the haemolymph free sugar level. All three physiological actions of ZopatNVPL-4trunc. are new activities for this group of peptides. NVPL-4trunc. inhibited the hindgut and ejaculatory duct 
contractions and showed the hyperglycaemic properties. Our comparative studies showed that all three tested peptides posses pleiotropic activities in regulation of the visceral organ muscle contractions and the free sugar level in the haemolymph.

Acknowledgments This work was supported by grant No. NN303401636 from the Polish Ministry of Science and Higher Education. PM was supported by City of Poznan Fellowship and Kulczyks' Family Fellowship.

Open Access This article is distributed under the terms of the Creative Commons Attribution Noncommercial License which permits any noncommercial use, distribution, and reproduction in any medium, provided the original author(s) and source are credited.

\section{References}

Audsley N, Weaver RJ (2006) Analysis of peptides in the brain and corpora cardiaca-corpora allata of the honey bee, Apis mellifera using MALDI-TOF mass spectrometry. Peptides 27:512-520

Audsley N, Weaver RJ (2009) Neuropeptides associated with the regulation of feeding in insects. Gen Comp Endocrinol 162:93-104

Clynen E, Schoofs L (2009) Peptidomic survey of the locust neuroendocrine system. Insect Biochem Mol Biol 39:491-507

Coast GM, Schooley DA (2010) Toward a consensus nomenclature for insect neuropeptides and peptide hormones. Peptides doi: 10.1016/j.peptides.2010.11.006

Cook BJ, Wagner RM (1991) Comparative effects of leucomyosuppressin on the visceral muscle systems of the cockroach Leucophaea maderae. Comp Biochem Physiol C 99:95-99

De Loof A (2008) Ecdysteroids, juvenile hormone and insect neuropeptides: recent successes and remaining major challenges. Gen Comp Endocrinol 155:3-13

Dubois M, Gilles KA, Hamilton JK, Rebers PA, Smith F (1956) Colorimetric method for determination of sugars and related substances. Anal Chem 28:350-356

Duve H, Rehfeld JF, East P, Thorpe A (1994) Localisation of sulfakinin neuronal pathways in the blowfly Calliphora vomitoria. Cell Tissue Res 275:177-186

Elia AJ, Orchard I (1995) Peptidergic innervation of leg muscles of the cockroach, Periplaneta americana (L), and a possible role in modulation of muscle contraction. J Comp Physiol A 176:425-435

Fields GB, Noble RL (1990) Solid-phase peptide synthesis utilizing 9 fluorenylmethoxycarbonyl amino acids. Int $\mathbf{J}$ Pept Protein Res 35:161-214

Fuse M, Orchard I (1998) The muscular contractions of the midgut of the cockroach, Diploptera punctata: effects of the insect neuropeptides proctolin and leucomyosuppressin. Regul Pept $77: 163-168$

Gäde G, Rosinski G (1990) The primary structure of the hypertrehalosemic neuropeptide from tenebrionid beetles: a novel member of the AKH/RPCH family. Peptides 11:455-459

Haselton AT, Yin CM, Stoffolano JG Jr (2006) The effects of Calliphora vomitoria tachykinin-I and the FMRFamide-related peptide perisulfakinin on female Phormia regina crop contractions, in vitro. J Insect Physiol 52:436-441

Holman GM, Cook BJ, Nachman RJ (1986) Primary structure and synthesis of a blocked myotropic neuropeptide isolated from the cockroach, Leucophaea maderae. Comp Biochem Physiol C $85: 219-224$

Hummon AB, Richmond TA, Verleyen P, Baggerman G, Huybrechts J, Ewing MA, Vierstraete E, Rodriguez-Zas SL, Schoofs L, Robinson GE, Sweedler JV (2006) From the genome to the proteome: uncovering peptides in the Apis brain. Science 314:647-649

Kimura T, Yasuyama K, Yamaguchi T (1989) Proctolinergic innervation of the accessory gland in male crickets (Gryllus bimaculatus) — detection of proctolin and some pharmacological properties of myogenically and neurogenically evoked contractions. J Insect Physiol 35:251-257

Lange AB, Orchard I, Tebrugge VA (1991) Evidence for the involvement of a SchistoFLRFamide like peptide in the neural control of locust oviduct. J Comp Physiol A 168:383-391

Li B, Predel R, Neupert S, Hauser F, Tanaka Y, Cazzamali G, Williamson M, Arakane Y, Verleyen P, Schoofs L, Schachtner J, Grimmelikhuijzen CJ, Park Y (2008) Genomics, transcriptomics, and peptidomics of neuropeptides and protein hormones in the red flour beetle Tribolium castaneum. Genome Res 18:113-122

Marciniak P, Rosinski G (2010) Comparison of proctolin and FMRFamide actions on the motility of male and female beetle reproductive tracts. Invertebr Reprod Dev 54:1-6

Marciniak P, Adamski Z, Bednarz P, Slocinska M, Ziemnicki K, Lelario F, Scrano L, Bufo SA (2010a) Cardioinhibitory properties of potato glycoalkaloids in beetles. Bull Environ Contam Toxicol 84:153-156

Marciniak P, Audsley N, Kuczer M, Rosinski G (2010b) Identification of myotropic neuropeptides from the brain and corpus cardiacum-corpus allatum complex of the beetle, Zophobas atratus. J Insect Sci 10:156

Nachman RJ, Holman GM, Haddon WF, Ling N (1986) Leucosulfakinin, a sulfated insect neuropeptide with homology to gastrin and cholecystokinin. Science 234:71-73

Nachman R, Giard W, Favrel P, Suresh T, Sreekumar S, Holman M (1997) Insect myosuppressins and sulfakinins stimulate release of the digestive enzyme $\alpha$-amylase in two invertebrates: the scallop Pecten maximus and insect Rhynchophorus ferrugineus. Ann N Y Acad Sci 814:335-338

Nässel DR (2002) Neuropeptides in the nervous system of Drosophila and other insects: multiple roles as neuromodulators and neurohormones. Prog Neurobiol 68:1-84

Nichols R (2007) The first nonsulfated sulfakinin activity reported suggests nsDSK acts in gut biology. Peptides 28:767-773

Nichols R, Bendena WG, Tobe SS (2002) Myotropic peptides in Drosophila melanogaster and the genes that encode them. J Neurogenet 16:1-28

Nichols R, Manoogian B, Walling E, Mispelon M (2009) Plasticity in the effects of sulfated and nonsulfated sulfakinin on heart contractions. Front Biosci 14:4035-4043

Orchard I, Lange A (2006) Insect myosuppressins/FMRFamides and FL/IRFamides/NPFs. In: Kastin AJ (ed) Handbook of biologically active peptides. Elsevier, Amsterdam, pp 193-199

Orchard I, Lange AB, Bendena WG (2001) FMRFamide-related peptides: a multifunctional family of structurally related neuropeptides in insects. Adv Insect Physiol 28:267-329

Peeff NM, Orchard I, Lange AB (1993) The effects of FMRFamiderelated peptides on an insect (Locusta-Migratoria) visceral muscle. J Insect Physiol 39:207-215

Predel R, Brandt W, Kellner R, Rapus J, Nachman RJ, Gäde G (1999) Post-translational modifications of the insect sulfakinins-sulfation, pyroglutamate-formation and O-methylation of glutamic acid. Eur J Biochem 263:552-560

Predel R, Russell WK, Russell DH, Lopez J, Esquivel J, Nachman RJ (2008) Comparative peptidomics of four related hemipteran 
species: pyrokinins, myosuppressin, corazonin, adipokinetic hormone, sNPF, and periviscerokinins. Peptides 29:162-167

Predel R, Neupert S, Garczynski SF, Crim JW, Brown MR, Russell WK, Kahnt J, Russell DH, Nachman RJ (2010) Neuropeptidomics of the mosquito Aedes aegypti. J Proteome Res 9:2006-2015

Quennedey A, Aribi N, Everaerts C, Delbecque JP (1995) Postembryonic development of Zophobas atratus Fab. (Coleoptera, Tenebrionidae) under crowded or isolated conditions and effects of juvenile hormone analog applications. J Insect Physiol 41:143-152

Rankin SM, TeBrugge VA, Murray JA, Schuler AM, Tobe SS (2009) Effects of selected neuropeptides, mating status and castration on male reproductive tract movements and immunolocalization of neuropeptides in earwigs. Comp Biochem Physiol A 152:83-90

Rosinski G, Gäde G (1988) Hyperglycemic and myoactive factors in the corpora cardiaca of the Mealworm, Tenebrio molitor. J Insect Physiol 34:1035-1042

Schoofs L, Nachman R (2006) Sulfakinins. In: Kastin AJ (ed) Handbook of biologically active peptides. Elsevier, Amsterdam, pp 183-187

Skonieczna M (2006) FMRFamide-related peptides and their biological functions in beetles. Adam Mickiewicz University, $\mathrm{PhD}$ Thesis, pp 1-104
Skonieczna M, Rosinski G (2004) Cardioactive effect of FMRFamide related peptides in beetles, Tenebrio molitor and Zophobas atratus. Pesticides 3-4:33-39

Slama K, Rosinski G (2005) Delayed pharmacological effects of proctolin and CCAP on heartbeat in pupae of the tobacco hornworm, Manduca sexta. Physiol Entomol 30:14-28

Sliwowska J, Rosinski G, Nässel DR (2001) Cardioacceleratory action of tachykinin-related neuropeptides and proctolin in two coleopteran insect species. Peptides 22:209-217

Verleyen P, Huybrechts J, Sas F, Clynen E, Baggerman G, De Loof A, Schoofs L (2004) Neuropeptidomics of the grey flesh fly, Neobellieria bullata. Biochem Biophys Res Commun 316:763-770

Vullings HG, Ten Voorde SE, Passier PC, Diederen JH, Van Der Horst DJ, Nässel DR (1998) A possible role of SchistoFLRFamide in inhibition of adipokinetic hormone release from locust corpora cardiaca. J Neurocytol 27:901-913

Wasielewski O, Skonieczna M (2008) Pleiotropic effects of the neuropeptides CCAP and myosuppressin in the beetle, Tenebrio molitor L. J Comp Physiol B 178:877-885

Weaver RJ, Audsley N (2008) Neuropeptides of the beetle, Tenebrio molitor identified using MALDI-TOF mass spectrometry and deduced sequences from the Tribolium castaneum genome. Peptides 29:168-178 